\title{
Los Encinos de México
}

Por el profesor Maximino Martinez.

Los encinos (Quercus) son de gran importancia en México, tanto por su abundancia, como por su utilidad como especies forestales.

Lo que hasta la fecha hay publicado sobre encinos consta en publicaciones extranjeras, principalmente en inglés y francés, y casi nada en español, por lo cual, ya que no sea posible publicar ahora un trabajo de conjunto, creo que será de utilidad presentar en español la descripción de las especies que están mejor definidas.

En esta primera contribución se mencionan los caracteres generales, y se da una idea del estado actual de la taxonomía y la descripción die . algunas especies aunque no en riguroso orden sistemático, a reserva de añadir nuevos datos a medida que aumente el material de estudio, y de presentar en una contribución posterior un cuadro de clasificación ya revisado, así como esquemas de distribución geográfica y las claves respectivas.

Para realizar este trabajo, que pudiera llamarse ensayo preliminar, tengo a la vista las obras que se han escrito sobre encinos, como las de Michaux, Humboldt y Bonpland, Liebmann y Oersted, De Candolle, Sargent, Trelease y otros, y los modernos estudios del doctor C. H. Muller.

Además, he examinado los ejemplares que existen en el Herbario Nacional, los que se han recibido recientemente de diversas zonas del país y los colectados por mi y por varios colaboradores, a quienes agradezco su generosa ayuda.

\section{Historia}

Hasta el siglo XVIII los encinos eran apenas conocidos desde el punto de vista botánico, de modo que solamente pocas especies se describieron 
en la época de Linneo, en cuya obra Species Plantarum, 1753, se nombran 9 (que posteriormente se han reducido a 5) correspondientes a Europa y a 4 a Norteamérica, siendo estas últimas Quercus alba, Q. rubra $Q$. Prinus y $Q$. Phellos.

Las publicaciones relativas al género Quercus aparecieron al comenzar el siglo XIX, habiendo sido la primera la de André Michaux "LesChénes de l'Amérique Septentrionale" (46 pp. de texto y 36 láminas. París, 1801), donde se describen 20 especies de los Estados Unidos Norteamericanos. André Francois Michaux, que durante algún tiempo viajó con su padre en ese país, publicó a su vez, de 1810 a 1813, la obra "Histoire des arbres Forestiéres de l'Amérique Septentrionale".

Aparecieron por aquella época los trabajos de Louis Née, quien dió noticia de los encinos de México y California, 16 especies que se publicaron en las Anales de Ciencias Naturales, Madrid, 1802.

Siguió la obra de Alejandro Humboldt y Aimé Bonpland "Plantes Aequinoxiales", 1808-1816, donde se nombran 17 especies.

Schiede, quien vivió en México de 1828 a 1836, exploró parte de los Estados de Veracruz y Morelos y describió 5 especies que Schlechtendal y Chamiso publicaron en Linnaea en 1830.

Henry Galeotti viajó en el país de 1835 a 1840 y publicó 10 especies con la colaboración de Martius en el Bulletin de l'Academie Royale de Bruxelles, vols. IX y XI.

En 1864 apareció la monumental obra de A. De Candolle "Prodromus Systematis Naturalis Regni Vegetabilis", en la que presenta un trabajo de conjunto y que puede considerarse como la mejor contribución del siglo XIX.

En 1869 apareció la magnífica obra de Frederik Michael Liebmann "Les Chenes de l'América Tropicale", bellamente ilustrada, que publicó Oersted en Copenhague tres años después de la muerte de Liebmann y donde se describen 52 especies. Oersted mismo viajó en la América Central y dió a conocer 5 especies. Igual cifra fué aportada por Warszewicz, quien viajó en parte en compañía de Oersted.

Liebmann publicó también "Les Chenes du Mexique", en la que utilizó los dibujos de los ejemplares de Née. (Overs. O. d. K. d. Videnk's Forhandlinger. 1854.)

Kellog y Green publicaron en 1889 una obra intitulada "Ilustrations of West American Oaks", y Sargent, en 1895, escribió en su "Silva of North 
America" (vol. XIII) un apreciable estudio sobre los Quercus de los Estados Unidos Norteamericanos.

En 1924 William Trelease publicó su importante y básico trabajo "The American Oaks" (255 pp. y 420 láminas ilustrando los tipos, en el vol. XX de las Memorias de la Academia Nacional de Ciencias de Washington), obra en que consigna la cifra de 632 entre especies, variedades y formas existentes desde los Estados Unidos hasta la América Central, agrupándolas en 131 sseries. Es seguro que en una nueva revisión del género y con más abundante material de estudio, la cifra consignada por Trelease tendrá que reducirse considerablemente.

Los trabajos más recientes sobre encinos son los del doctor C. $\mathrm{H}$. Muller, especialmente el que se intitula "The Central American Species of Quercus" (U. S. Dept. of Agr. Publ. 477. 1942. 92 pp., 124 ilustraciones). Introduce algunas series y pasa a sinonimia algunas de las establecidas por Trelease.

El mismo autor ha publicado numerosos artículos en American Midland Naturalist, Journal del Arnold Arboretum y Bull. of the Torrey Botanical Club.

Descripción general del género

Arbustos, arbolillos o árboles; ramillas más o menos acanaladas; yemas aglomeradas hacia la extremidad de las ramillas, con estípulas subuladas o liguladas, comúnmente caedizas; hojas alternas, cortamente pecioladas, enteras, dentadas o lobadas; flores apétalas; las masculinas en amentos, con cáliz de 5 lóbulos unidos; 4 a 12 estambres de filamentos delgados; las femeninas en corto número, sobre un eje más o menos largo, con el cáliz de 6 piezas unidas a la base de los estilos; ovario tricarpelar y trilocular, con 2 óvulos en cada lóculo; estilos 3, estigmatíferos ventralmente hacia el ápice. Fruto con una semilla por atrofia de las otras 5, las cuales quedan adheridas a ella; fruto colocado en un invólucro escamoso.

Porte.-Las dimensiones de los encinos varían según las especies: algunos son árboles corpulentos y majestuosos, de amplio follaje; otros son arbolillos de 3 a 4 metros y, finalmente, hay especies enanas, de 10 a 60 $\mathrm{cm}$. de altura. También varía el tamaño según las condiciones del medio: algunas especies, cuando logran vivir en suelos pobres, disminuyen su altura. Las especies que viven en el Valle de México en su mayoría son arbolillos. 
Los encinos son de crecimiento muy lento y alcanzan larga vida. En el Hiloche, Hgo., se ven ejemplares enormes que probablemente pasan de 500 años.

Corteza.-La de los encinos negros (Erythrobalanus) es gruesa y hendida, de color rojizo, amarga $y^{\prime}$ astringente. Contiene gran cantidad de tanino, por lo que se usa mucho en curtiduría. También se usa en la medicina popular para endurecer las encías. La de los encinos blancos (Lepidobalanus) es rasgada, grisácea y relativamente delgada.

Yemas.-Son generalmente muy pequeñas y están protegidas por escamas imbricadas. Son de forma ovoide, cónica o globosa, con la superficie lisa o tomentosa. Esos y otros caracteres observados en las yemas frescas, pueden servir como elemento sistemático.

Ramillas.-Son más o menos acanaladas y en su superficie se notan lentejuelas bien visibles en unos casos y poco marcadas en otros.

Hojas.-Las hojas de los encinos son alternas, tiesas y coriáceas, y muy variadas en su forma y tamaño, lo mismo que en el color, predominando el verde en todas sus tonalidades, pero en algunas especies son glaucas o azulosas; en otras las hojas tiernas son de color rojizo o rojizo violáceo. Las hay de borde entero, aserrado o dentado, ondulado o lobulado; a veces los dientes se prolongan en puntas agudas. He notado que, a diferencia de varias especies norteamericanas, las de México no son profundamente lobuladas. El ápice es gradual o bruscamente agudo, a veces redondeado, mucronado o escotado. El pecíolo comúnmente es corto y de sección transversal, circular o elíptica; lleva dos estípulas laterales pronto caedizas. E1 limbo mide desde 1 ó $2 \mathrm{~cm}$. de largo (Quercus striatula y $Q$. Toumeyi) hasta $40 \mathrm{~cm}$. o algo más (Quecus macrophylla). Por su figura, el limbo puede ser oval, elíptico, ovado, obovado, lanceolado, etc., pero la forma es constante en la gran mayoría de las especies. La base puede ser cordada, escotada o cuneada.

Las nervaduras son hundidas y a veces poco visibles en la cara superior y salientes en la inferior; de la central parten, opuestas o alternas, las nervaduras laterales, las cuales se dirigen hacia el borde, encorvándose más o menos, anastomosándose o rematando en los dientes cuando éstos existen; de ellas salen nervaduras secundarias que a su vez se subdividen más y más, formando un retículo, visible sobre todo en la superficie inferior.

En algunos casos las hojas caen casi en una misma época quedando el árbol poco menos que desprovisto de follaje (hojas caducas): en otros 


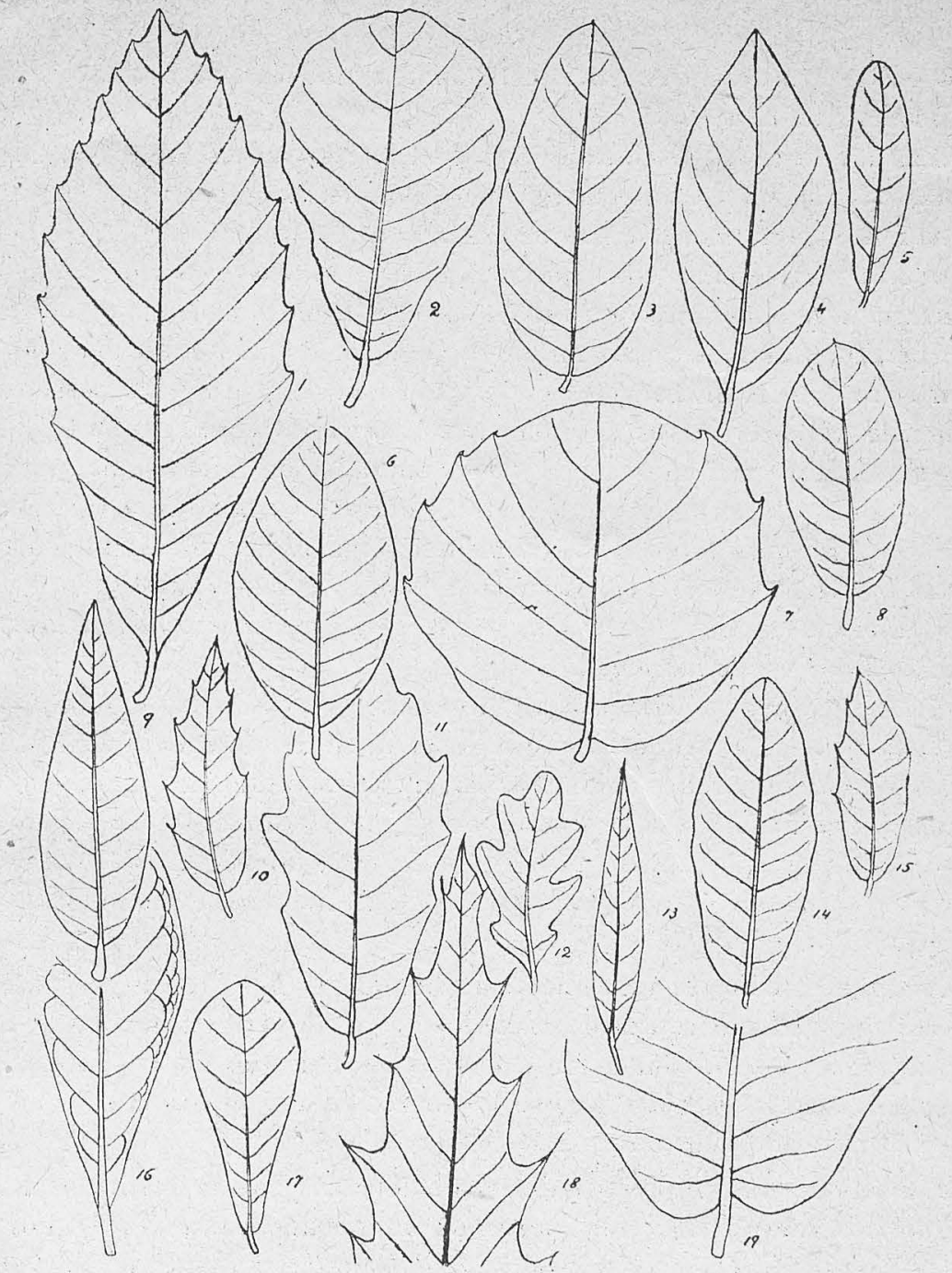

Fig. 1. Diversas formas de hojas de encinos. 1, Quercus Galeottii: hojas de borde dentado y base cuneada. 2, Q. crenatifolia: hoja abovada, de borde ondulado y base redondeada. 3, Q polymorpha: hoja largamente ovada, de ápice mucronado. 4, Q. laurina: hoja anchamente elíptica y brevemente acuminada. 5, Q. totutlensis: hoja elíptica de ápice redondeado. 6, Q. Lecomteana: hoja oval de ápice redondeado. 7, Q. Conzattii: hoja orbicular con dientes agudos. 8, Q. praineana: hoja oval de ápice mucronado y base redondeada. 9, Q. Giesbreghtii: hoja lanceolada de borde entero y base redondeada. 10, Q. devia: hoja lanceolada de borde aristado. 11,.. . panduriformis: hoja de base redondeada y borde gruesamente dentado. 12, Q. venustula: hoja lobulada. 13, Q. hypoleuca: hoja lanceolada Iargamente acuminada. 14, $Q$. baldoquinae: hoja elíptica de borde irrgeularmente ondulado. 15, Q. Emoryi: hoja de borde irregularmente dentado aristado. 16, $Q$. lanceolata: hoja con las nervaduras anastomosadas cerca del borde. $17, Q$. ovatifolia: hoja obovada. 18, Q. acutifolia: hoja de borde aristado dentado. 
casos caen a medida que envejecen, apareciendo el árbol siempre verde (hojas persistentes).

Las hojas en su estado juvenil suelen ser pubescentes, volviéndose glabras después, pero es frecuente que conserven la pubescencia en lá forma adulta, especialmente en la cara inferior.

Flores.-Los encinos son plantas monoicas, es decir, sus flores son masculinas unas y femeninas otras en el mismo árbol. Ambas clases de flores son apétalas. Las masculinas nacen en la axila de las yemas del año anterior y se presentan en amentos, o sean ejes delgados y colgantes, con frecuencia vellosos, donde se encuentran las flores colocadas a to largo. Constan de un cáliz monosépalo, campanulado, de 5 divisiones unidas; los estambres son normalmente 6 , pero el número varía entre 4 y 12 , insertados en el receptáculo, con los filamentos largos y las anteras biloculares, exertas y a veces vellosas, como en las especies de la sección Virentes y en Barbanthera, centralis, deserticola, glaucoides, laxa, macrophylla, Martensiana, salicifolia y tahuasalana.

Las femeninas se producen en pequeños grupos en las ramillas jóvenes; constan de un cáliz de seis divisiones distintas; ovario ínfero de tres lóculos biovulados, rodeado de un invólucro escamoso (cúpula), con las escamas fuertemente unidas, al grado de que en ocasiones se ven solamente como picos o protuberancias. Los estilos son tres, unidos en la base. Generalmente de los seis óvulos solamente se desarrolla uno, quedando los demás atrofiados.

Aunque el fruto es únicamente la bellota, la mayoría de los autores admiten que el fruto consta de la bellota y la cúpula. Madura en el mismo año en los encinos blancos y en el término de dos en la mayoría de los encinos negros. El Quercus Emoryi, por ejemplo, siendo encino negro, madura su fruto en un año.

La bellota es oval, subovoide o subglobosa, y en la clasificación de los frutos se consideraría como aquenio. Su tamaño varía desde unós 10 mm. (Q. Emoryi, Q. Urbani y $Q$. coccolobaefolia) hasta cerca de $9 \mathrm{~cm}$. (Q. ovandensis); tiene una cicatriz circular en la parte donde se une con la cúpula y una punta dura formada por la base de los estilos. El pericarpio o sea la cáscara de la bellota, es liso o finamente tomentoso por fuera, pero por dentro es tomentoso o casi lanoso en Erythrobalanus y liso en Lepidobalanus. Al separar la cáscara se ve la semilla procedente del único óvulo desarrollado, y los otros cinco atrofiados, colocados hacia la base en el caso de los encinos blancos y hacia el ápice en el de los enci- 
nos negros, salvo en algunos de estos últimos, como los de las secciones Durifoliae, Scytophyllae, Hypoleucae y Costarricenses, en que en vez de ser apicales son basales o se distribuyen a lo largo de la semilla.

Sin embargo de que, como se ha dicho, solamente se desarrolla un óvulo, se han visto casos en que se desarrollan de 2 a 5 . El doctor J. T. Buchholtz (Ill. Acad. of Sci. Trans. 34. 2. 1941) habla de "multiseeded
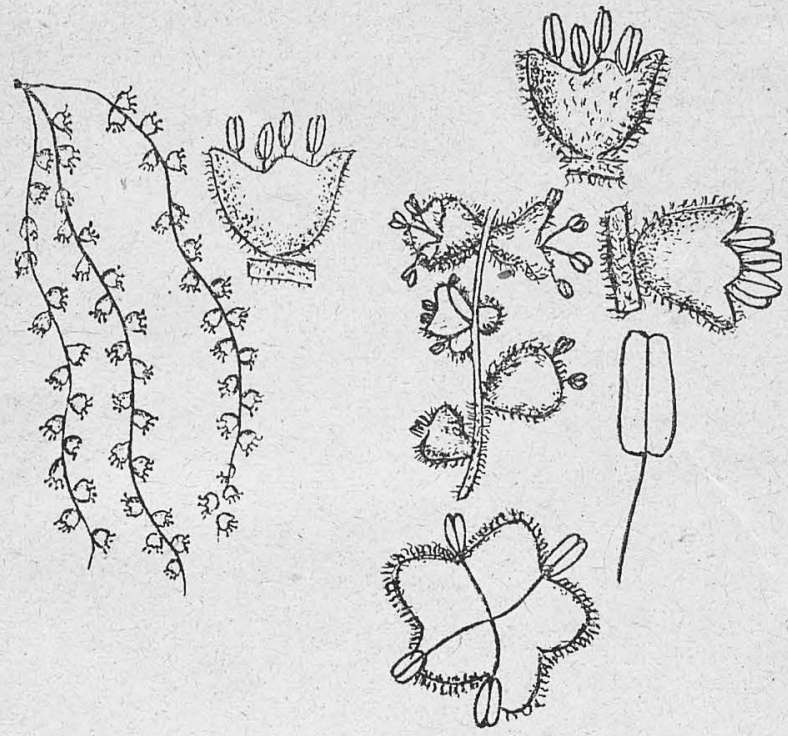

Fig. 2. Amento masculino y flor femenina. Detalle del amento masculino.

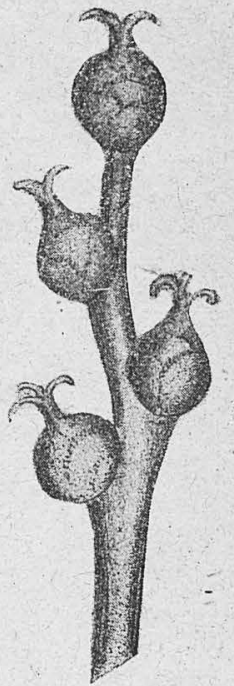

Fig. 3. Amento femenino.

acorns" (bellotas con varias semillas). Observó un Quercus falcata Michx. en Conway, Arkansas, cuyas bellotas tenian varias semillas, y esto no excepcionalmente en determinada época, sino al parecer constantemente, a lo menos de 1917 a 1940. Dice el autor que de 77 bellotas que examinó en 1940, 40 tenian una semilla y 37 de 2 a 5 .

La cúpula tiene la forma de platito o de copa de profundidad variable según las especies, y en ella queda sumergida la bellota, en algunos casos un tercio y en otros un medio o más.

Los cotiledones son plano-convexos, lisos o algo rugosos, de color blanco o amarillento y en algunas especies violáceo. El embrión es carnoso y sin albumen, con la radícula súpera. 
Propagación--Los encinos se propagan por semillas, debiendo sembrarse lo más pronto posible, pues dura muy poco tiempo su poder germinativo. Aparece la raíz y hasta que se ha desarrollado bastante, a veces después de algunos meses, emerge el talluelo. Se sabe que pueden injertarse, pero ese procedimiento no se ha intentado en México, que yo sepa.

Lugares donde regetan.-Los encinos son propios de las regiones templadas y frías y del hemisferio norte, y de las montañas elevadas de los

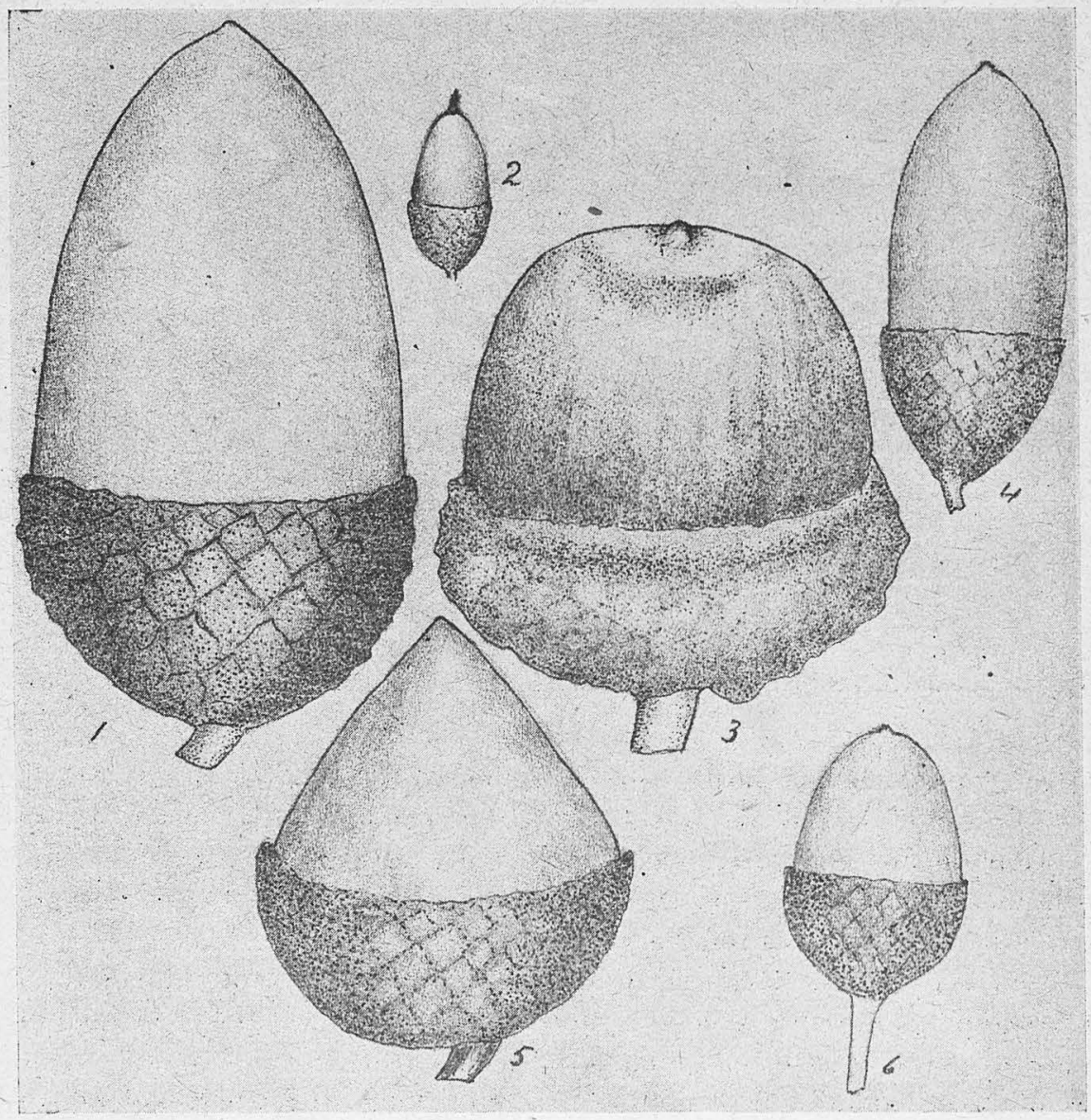

Fig. 4. Diversos frutos: 1, Quercus ovandensis; 2, Q. Emoryi; 3, Q. chiapasensis; . 4, Q. boqueronae; 5, Q. corrugata; 6, Q. leiophylla. (Todo de tamaño natural). 
trópicos. Prosperan en terrenos moderadamente fértiles y húmedos, pero algunas especies se adaptan a terrenos pobres, aunqué siempre en lugares montañosos. En lo general se ven desde 2,000 metros de altura o más.

Nombres vulgares.-Popularmente en algunas regiones usan el nombre encino para las especies de hojas persistentes, y el nombre roble para las de hojas caducas. Se oyen, además, otros nombres como "charrasquillo" aplicado a los que son arbustos, "encinilla" a las especies enanas; "ahoatl", palabra azteca; "ndeza" en lengua otomi; "yaga cino" en lengua zapoteca, etc.

Son tan variables los nombres vulgares según las regiones, que solamente conviene emplearlos en casos especiales.

\section{Utilidad:}

Flores.--El cocimiento de los amentos masculinos tiene uso en la medicina popular como antiespasmódico y contra los vértigos y la epilepsia.

Bellotas.-En lo general son de sabor astringente y desagradable y no son comestibles para el hombre, pero varios animales las comen bien, especialmente los cerdos; sin embargo, en el caso del Quercus Emoryi de Sonora y Chihuahua, la semilla se puede comer cocida o cruda, siendo su sabor amiláceo, dúlzón y ligeramente amargo; contiene almidón, grasa, azúcar y substancias astrinentes. Para quitarles ese sabor: amargo se descascaran y después de molerlas se lavan con agua tibia dos o tres veces; la harina que resulta se puede usar sola o mezclada con la de trigo para hacer galletas.

Las de otras especies se torrifican y se muelen, obteniéndose así el café de bellota, usado en medicina como astringente.

Madera.-Aunque sus características varían según las especies, en lo general es fuerte y durable, susceptible de hermoso pulimento y muy preferida para muebles, construcciones terrestres y navales, mangos de herramientas, etc., y para hacer carbón, el cual resulta de calidad superior al que se hace con otras maderas. Tiene grandes vasos aglomerados en los anillos de crecimiento, y los radios medulares son bien visibles; unos largos y toscos y otros cortos y finos.

Se hace considerable tala de encinos, por lo cual corren péligro de extinción, principalmente las especies de gran talla. Para substituir la corteza se podría impulsar la propagación del "palo blanco" (Lysiloma 
candida), el "mauto" (Lysiloma divaricata), el "cascalote" (Caesalpinia coriaria y $C$. cacalaco) y otras plantas tanantes.

Para substituir el carbón de encino podría usarse el de otras plantas, como la Acacia decurrens, mientras se generaliza el uso del combustible mineral.

Agallas.-Los encinos con frecuencia producen agallas o sean unos abultamientos teratológicos que aparecen en las hojas. A veces son esféricas, de 2 a $8 \mathrm{~cm}$. de diámetro y de hermosos colores. Tales agallas son provocadas por la picadura de un insecto de la lamilia Cynipidae, cuya larva se desarrolla en el interior. Las agallas contienen, en algunos casos, de 60 a $70 \%$ de tanino, por lo que tienen uso industrial y medicinal.

El profesor Pascual Alcocer, en su estudio "Algunos principios astringentes vegetales" (La Naturaleza, VII, p. 116. México, 1887), dice que las agallas contienen ácido galotánico, inodoro e incristalizable, que se presenta en forma de escamas brillantes, de sabor astringente; es soluble en el agua y en el alcohol débil, insoluble en el éter y en el alcohol puro; precipita las soluciones albuminosas y gelatinosas.

El citado autor calculó en las agallas de encino $16 \%$ de ácido tánico y $9.5 \%$ de ácido gálico.

\section{Clasificación}

Pertenecen los encinos a la familia de las Fagáceas. Esta familia comprende 2 secciones:

I. Fageae.

II. Castaneae.

La Sección Fageae comprende dos géneros:

1. Nothophagus, con 12 especies de América del Sur, hacia la región antártica, y de Australia. En Chapultepec hay algunos ejemplares cultivados.

2. Fagus, con unas 8 especies de Europa y América del Norte. En México hay solamente una especie (Fagus mexicana), en Hidalgo y Tamaulipas.

La Sección Castaneae incluye 4 géneros:

3. Castanea, con unas 30 especies de Europa, Asia y Estados Unidos norteamericanos.

4. Pasania, con unas 100 especies de Asia, Nueva Zelanda y Estados Unidos norteamericanos. 
5. Castanopsis, con 25 especies de las montañas tropicales y subtropicales de Asia y 1 de América del Norte.

6. Quercus, con cerca de 500 especies de las regiones templadas y subtropicales de Asia, Europa y América, principalmente de México.

La colocación de los encinos en la escala vegetal-es como sigue:

División. . . . Embriophyta siphonogama

Subdivisión . . Angiospermae

Clase . . . . Dicotyledoneae

Subclase . . . Apetalae

Orden . . . Fagales

Familia . . . Fagaceae

Sección . . Castaneae

Género . . . Quercus

El género Quercus comprende tres subgéneros:

1. Lepidobalanus.

II. Protobalanus.

III. Erythrobalanus.

En seguida se mencionan los caracteres de estos subgéneros:
Lepidobalanus
Protobalanus
Erythrobalanus

El fruto madura el mismo

A $\operatorname{los} 2$ años.

A los dos años o uno. año.

La superficie interna de la Lanosa.

Lanosa.

cáscara de la bellota es lisa.

Los óvulos atrofiados son Laterales. basales.

Estigmas cortos y anchos, casi sésiles.

Escamas de la cúpula muy engrosadas en la base, más o menos aquilladas, con las puntas angostas.

Corteza del tronco delgada, comúnmente gris $y$ escamosa.

Dilatados sobre estilos cortos.

Algo gruesas, frecuentemente lanosas y puntiagudas.

Delgada, escamo- Gruesa, obscura, profundasa, moreno grisácea.
Apicales o laterales, rara vez basales.

Espatulados, sobre estilos alargados.

Delgadas y aplanadas, no aquilladas. mente hendida, dura. 
Estos tres subgéneros están divididos en 131 secciones, de las cuales corresponden 57 a Lepidobalanus, 1 a Protobalanus y 75 a Erythrobalanus.

Contando los encinos que se consignan en las obras más recientes, se llega a la cifra de 447 entre especies, variedades y formas en México y Centroamérica, de las cuales correspondian 221 a Lepidobalanus; 7 a Protobalanus y 219 a Erythrobalanus.

Para abarcar la distribución anterior de un golpe de vista, véase el cuadro siguiente:

\begin{tabular}{clrr} 
Género & \multicolumn{1}{c}{ Subgéneros } & Secciones & $\begin{array}{r}\text { Especies } \\
\text { dades y }\end{array}$ \\
\multirow{4}{*}{ Quercus } & Lepidobalanus & & 221 \\
& Protobalanus & 57 & \\
& Erythrobalanus & 1 & 219 \\
& & 73 & - \\
& & 121 & 447
\end{tabular}

Debo hacer notar que las cifras mencionadas no son definitivas, porque no se ha reunido suficiente material para emprender un estudio detallado, pero puede anticiparse que, al revisar el género con detenimiento, esas cifras, sobre todo la última, se reducirán considerablemente, quizá en un $30 \%$. Hay, en efecto, muchas especies insuficientemente definidas, por falta de oportunidad para una observación directa y detallada en diferentes épocas, que permita obtener algunos datos morfológicos.

A continuación vendrán las descripciones de algunas especies sin seguir un orden rigurosamente sistemático, sino dando preferencia a las principales por su abundancia, por su utlidad y porque están ya bien definidas desde el punto de vista botánico.

\section{Quercus Emoryi Torr.}

Subgénero Erythrobalanus.

Sección Durifoliae.

En los mercados de la región norte de Sonora y Chihuahua son bien conocidas y muy populares ciertas bellotas comestibles, de sabor agradable. Ocasionalmente las reciben aquí en la capital algunas personas nativas de aquellos Estados, quienes suelen comerlas como si fueran cacahuates. 


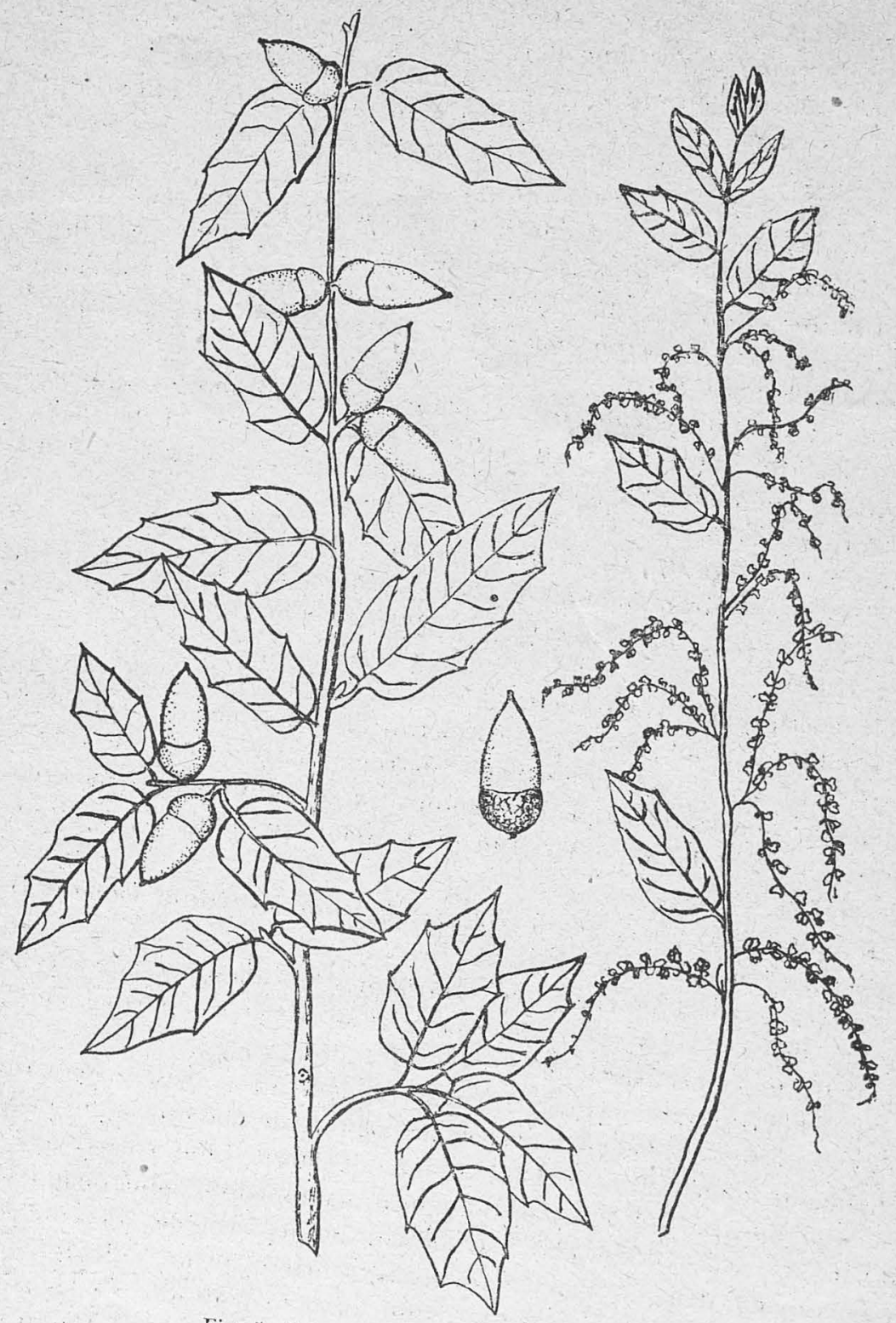

Fig. 5, Quercus Emoryi (tamaño natural). 
Se trata de una bellota pequeña, elíptica, de 15 a $20 \mathrm{~mm}$. de largo, de cáscara delgada, con la almendra amilácea, dulzona, grasosa y agradable. Estas últimas cualidades son excepcionales en las bellotas por mi conocidas, las cuales generalmente tienen gran proporción de tanino, que las hace ásperas, amargas, astringentes, desagradables para, el hombre y solamente útiles para la alimentación de los cerdos.

El señor Dudley Gold, miembro de la Sociedad Botánica de México, tuvo la bondad de poner a mi disposición hojas y flores, y así pude llegar a la conclusión de que las aludidas bellotas son producidas por un encino llamado vulgarmente "encino negro", que corresponde a la especie botánica Quercus Emoryi Torr.

Buscando los antecedentes de esta planta he encontrado los siguientes:

Fué descrito por John Torrey (Rept. Emory, p. 151. pl. 9. 1948) y tiene como sinónimo Quercus hastata Liebm. (Overs. Dansk. Vidensk. Selsk. Forhandl. 1854. p. 171, 1854).

Según el doctor C. H. Muller (Journ. Arn. Arb. XXV, 4, p. 448. Oct. 1944) son también sinónimos: Quercus Duraznillo Trel. (Mem. Nat. Acad. XX. p. 122. t. 220 y 221. 1924) y Quercus balsequillana Trel. (ibid. p. 123. t. 220).

Su descripción es como sigue:

Arbolillo o árbol de unos cinco metros de altura en los lugares secos y hasta cerca de 15 en terrenos bajos y fértiles, con tronco de 30 a $90 \mathrm{~cm}$. de diámetro; de corteza áspera y hendida en los adultos, con lentejuelas escasas y poco notables, interiormente moreno rojiza, de 25 a $50 \mathrm{~mm}$. de grueso.

Ramillas algo estriadas, de color rojizo con leve tinte violáceo, con la superficie tomentosa en sus partes tiernas.

Yemas ovoides, morenas, lisas y brillantes, de unos tres $\mathrm{mm}$. de largo por dos de ancho las observadas, pero al desarrollarse pueden alcanzar 8 por $3 \mathrm{~mm}$. respectivamente.

Las hojas durante hasta la primavera siguiente o más, y son gruesas y duras, elípticas, oblongas u ovadas, de color verde obscuro, sobre peciolos densamente tomentosos, de unos $4 \mathrm{~mm}$. de largo. Limbo de 3 a $7 \mathrm{~cm}$. de largo por 1.5 a 2.5 de ancho; ápice acuminado y mucronado; base cordada o algo redondeada o truncada; borde variable, ya entero, ya desigualmente dentado, con los dientecillos más o menos salientes y agudos; cuando jóvenes cubiertas con denso tomento plateado; en las adultas la cara superior lisa y brillante, puberulenta únicamente a lo largo de la 
nervadura central; la cara inferior algo opaca, tomentosa, sobre todo en la parte cercana al pecíolo; nervaduras laterales poco encorvadas, de 8 a 10 a cada lado, vagamente reticuladas y anastomosadas cerca del borde, prolongándose algunas en los dientecillos.

Amentos masculinos de unos $40 \mathrm{~mm}$. de largo, con periantio pálido lanoso, con 4 a 5 lóbulos y 4 anteras grandes, glabras y redondeadas, poco exertas.

Flores femeninas casi sésiles, con las escamas cubiertas de tomento.

Fruto anual, solitario o por pares, verdoso al principio y moreno después subsésil o sobre pedúnculo muy corto; elipsoide, con una cicatriz saliente bien visible en el ápice; de cáscara delgada y frágil, inte riormente tomentosa; de 15 a $20 \mathrm{~mm}$. de largo por 8 de ancho, con el tercio inferior incluído en una cúpula de unos $10 \mathrm{~mm}$. de diámetro, con escamas apretadas, romas y canescentes. Madura en el mismo año, de junio a agosto. La cáscara es frágil y la almendra de sabor agradable, seguramente de apreciable valor nutritivo. Los antiguos indígenas usaron estas almendras como alimento y en la actualidad es uso popular comerlas crudas o mezclarlas con harina para hacer galletas.

La madera es dura y pesada, resistente, pero algo quebradiza, de estructura fina y de color moreno obscuro, con peso específico de 0.93 .

Se encuentra en Texas, Nuevo México, Arizona, y en nuestros Estados de Sonora, Chihuahua y Coahuila, entre los 1,000 y 2,000 metras.

Localidades:

Cerca de Cananea, Son. (Dudley Gold. Mayo de 1949).

Cerca de Nogales, Son. (Griffiths).

Sierra del Pajarito, Son. (Scott).

Entre Chihuahua y el Río de S. Pedro, Chih. Colector? 1930. Ejemplar del Herbario Nacional!

Cerca de Chihuahua (Palmer 359).

Paso de Carneros, Coah. (Pringle 2802. 15 de septiembre de 1889)! A lo largo de la Sierra Madre de Chihuahua y Sonora (C. H. Muller). Según la Check List of the Trees of the U. S. 1944, existe también en Nuevo León, de donde se registró como Quercus Duraznillo.

El tipo se encuentra en el New York Botanical Garden.

Si Quercus Duraznillo Trel. y Quercus balsequillana Trel. son, como lo dice Muller, sinónimos de Quercus Emoryi Torr., hay que añadir las siguientes localidades citadas por Trelease:

Para Q. Duraznillo Trel.: 
De Agua Caliente a Balsequillo, Chih. (Endlich 1277).

De Baquiriáchic a La Jolla, Chih. (Endlich 1277 b. Abril 9 de 1906. Tipo).

De Balleza a Baquiriáchic, Chih. (Endlich 1279).

Cerro de Nanarúchic, Chih. (Endlich 1281).

Cusihuiriáchic, Chih. (Pringle 2112):

Quercus Urbani Trel. Proc. Am. Philosph. Soc. LX, p. 32, pl. 2. 1921. = Q. radiata Trel. Ibid p. 33 pl. 3. 1921.

Sección Racemiflorae.

Subgénero Erythrobalanus.

Arbol de 8 a 10 metros de altura, con el tronco tortuoso. Ramillas muy fuertes, de 5 a 7 y hasta $10 \mathrm{~mm}$. de grueso, acanaladas, cenicientas y finamente tomentosas, con numerosas lentejuelas obscuras. Yemas redondeadas $u$ ovales tomentosas, de unos $15 \mathrm{~mm}$. de largo. Hojas caedizas, orbiculares, acucharadas, de unos $30 \mathrm{~cm}$. de largo por 22 de ancho; ápice redondeado o cortamente acuminado; base cordado-auriculada; superficie superior convexa, de color verde claro, lisa; superficie inferior densamente lanosa; borde algo ondulado y con dientes pequeños y fuertes; pecíolo de 25 a $30 \mathrm{~mm}$., acanalado hacia el haz de la hoja; nervaduras unas 10 a cada lado, más o menos bifurcadas hacia el borde. Frutos anuales, colorados hacia la extremidad de un eje tomentoso amarillento, de 8 a $10 \mathrm{~cm}$. de largo y frecuentemente caedizo juntamente con las bellotas. Cúpula hemisférica, de $10 \mathrm{~mm}$. de diámetro, con las escamas apretadas y romas.

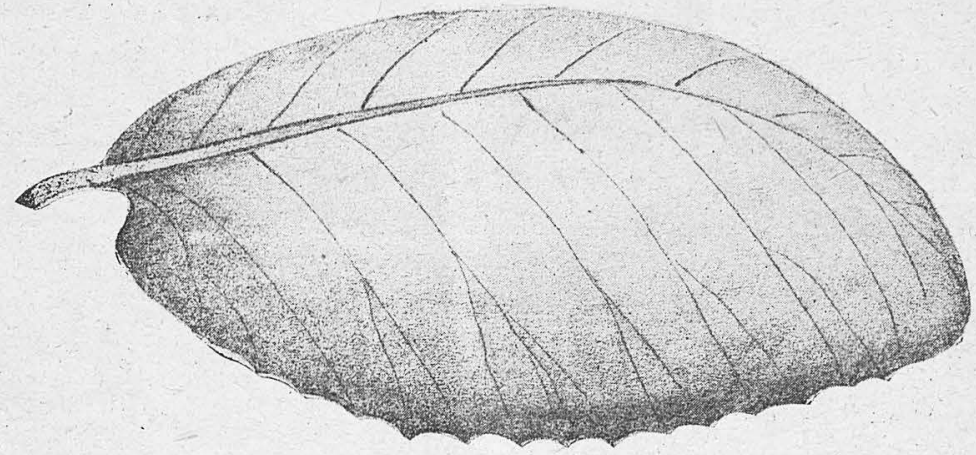

Fig. 7. Hoja de Quercus Urbani (1/3 del tamaño natural). 
Bellota ovoide, de $10 \mathrm{~mm}$. de largo, cenicienta, incluida un medio. "Encino cucharillo".

Localidades:

Cerca de Tasco, Gro., a 1,800 metros (Martínez):

Guerrero o Michoạcán (Langlassé, 1066. Tipó, en el Herbario de Berlin).

Cerca de Santa. Téresa, Nay. (Rose 2230. Agosto 13 de 1897. Tipo de Q. radiata).

Entre Casahuates y una presá al oeste de Tasco, Gro. - (H: E. Moore Jr. y C. E. Wood Jr. número 4579).

Cerro El Fuerte, Bacayopa, Choix, Sinaloa. Ramón Castro 2222. Noviembre 1951 .

Entre las colecciones que me fueron remitidas de Oaxaca por el señor Th. MacDougall en diciembre de 1952, encontré un encino que desde luego me pareció diferente de los descritos hasta la fecha, y que se distingue a primera vista por sus hojas aglomeradas; muy angostas y agudas.

Lo comparé con las especies admitidas y al fin resolvi describirlo, colocándolo en el subgénero Erythrobalanus, serie Eugeniaefoliae.

Quercus Mulleri sp. nova. (Anales del Instituto de Biología XXIV (1).

Arbol de 12 a 15 metros, a veces hasta 20, con follaje denso y brillante. Corteza obscura y algo lisa. Ramillas estrellado-puberulentas, pronto lisas, delgadas y acanaladas, moreno-obscuras y cenicientas, de 0.5 a $1 \mathrm{~mm}$. de grueso, con lentejuelas prominentes. Yemas ovoides o largamente ovoides, de color castaño, de 2 a $4 \mathrm{~mm}$. de largo por 1 a 2 de ancho, con las escamas ovadas, de borde ciliado. Hojas angostamente lanceoladas y largamente acuminadas, frecuentemente algo falcadas, de color verde claro, algo glaucas, al principio estrellado-tomentosas en ambas caras y pronto lisas, de 6 a $12 \mathrm{~cm}$. de largo por 7 a $20 \mathrm{~mm}$. de ancho; ápice largamente agudo; base cuneada; borde entero, algo engrosado, blanco y revoluto; en las hojas adultas la superficie superior es lisa y -brillante, con las nervaduras laterales casi invisibles y la central algo prominente; superficie inferior lisa y menos brillante, con la nervadura central muy prominente y las laterales bien visibles; nervaduras visibles a la simple vista de 25 a 30 a cada lado, Ia central prominente en ambas caras y las laterales delgadas y casi invisibles arriba y claras y salientes abajo, anastomosadas cerca del borde. Pecíolo de cerca de $2 \mathrm{~mm}$. de largo. Amentos masculinos de unos $5 \mathrm{~cm}$. de largo, con èl raquis velloso, casi filiforme, con flores amarillento-pajizas, 


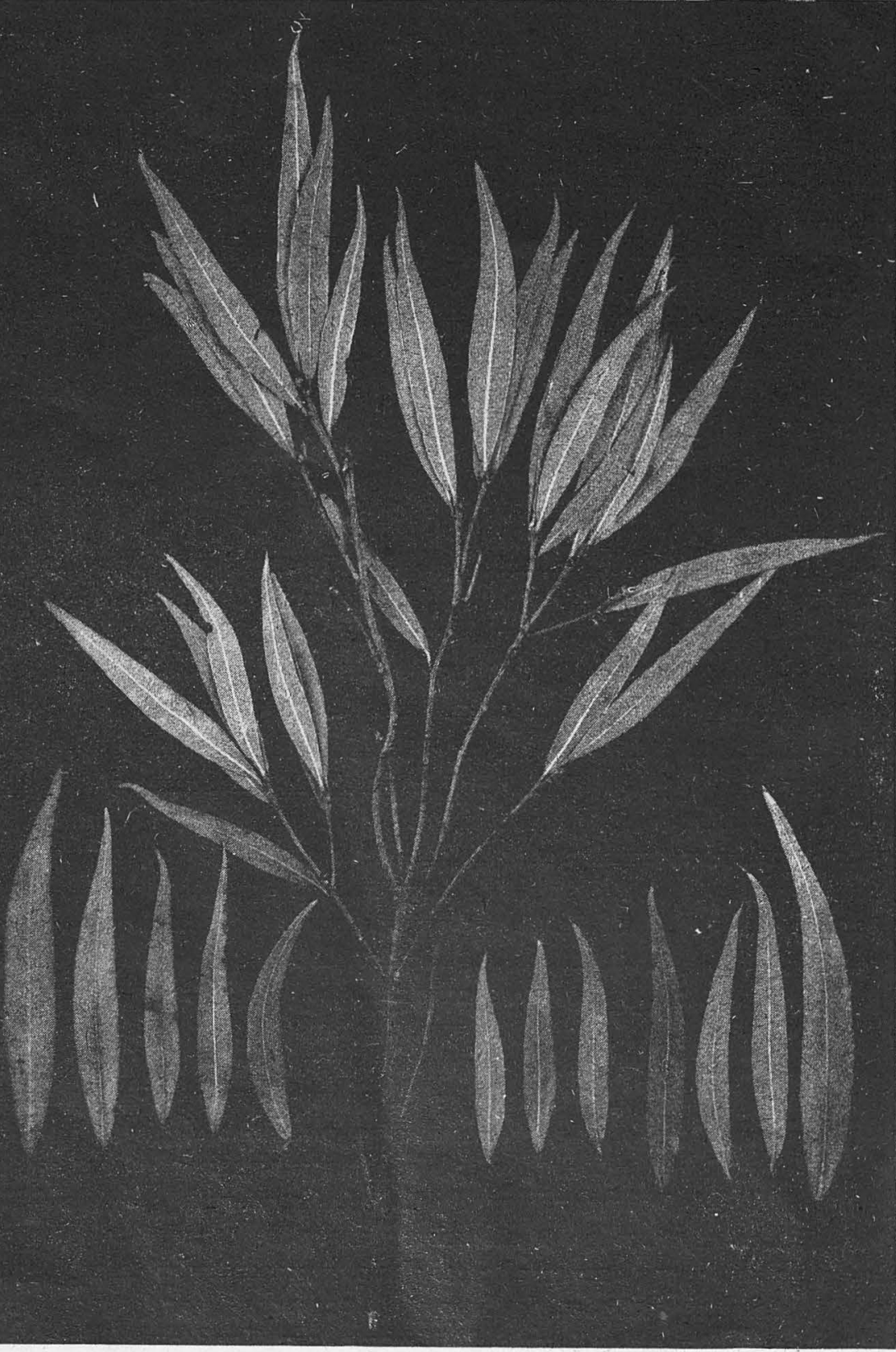

Fig. 1. Ramilla y hojas del Quercus Mulleri, aproximadamente $\times 3 / 4$. (Para claridad en la fotografía se quitaron muchas hojas, pues éstas son muy aglo. meradas.) 
con el perigonio de 4 segmentos, velloso-lanosos por fuera, que protegen 4 estambres. Amentos femeninos de cerca de $1 \mathrm{~cm}$. de largo, bilforos, con el pedúnculo liso. El fruto madura el mismo año, mide unos $17 \mathrm{~mm}$. y tiene pedúnculo breve. Cúpula turbinada, hasta de unos $7 \mathrm{~mm}$. de alto por 10 de ancho, cubierta de escamas ovadas y lisas. Bellota ovoide, hasta de unos $14 \mathrm{~mm}$. de largo por 9 de ancho, incluida aproximadamente un tercio.
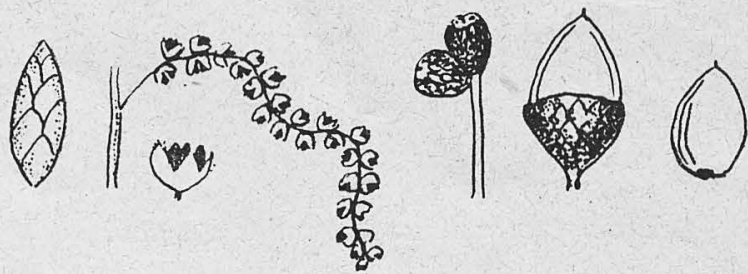

Fig. 2. Quercus Mulleri. Yemas, amento :masculino y flor; amento femenino, fruzo y beliota.

Se ha colectado entre San Pedro Sosoltepec y Tacubaya, Distrito de Yautepec, Oaxaca, aproximadamente entre los 96 grados de longitud y los 16.10 de latitud, en alturas de 1000 a 1300 metros. Mac Dougall, 2435, noviembre de 1952, y 2589, febrero 4 de 1953. Tipo en el Instituto de Biologia, México. Otra colección de MacDougall es el número 2500, en San Pablo Topiltepec (unos $15 \mathrm{Kms}$. al norte de San Pedro Sosoltepec), febrero de 1949. Se denominó en honor del Dr. C. H. Muller en reconocimiento de sus excelentes estudios sobre el género Quercus.

(Articulo publicado en los Anales del Instituto de Biologia Vol. XXIT. Se reproduce con autorización del Director). 